\title{
Quantitative Motor Assessment in Myotonic Dystrophy
}

\author{
J. Mathieu, H. Boivin, C.L. Richards
}

\begin{abstract}
Objective: To establish baseline data, using a quantitative motor evaluation protocol, prior to a prospective longitudinal study of the natural history of muscular involvement in myotonic dystrophy (DM). Design/Methods: We conducted a cross-sectional study using a protocol consisting of manual muscle testing (MMT), quantitative muscle testing (QMT), and timed functional testing (TFT) on 50 definite DM patients (27 men, 23 women), aged 16 to 67 years. The relationships between MMT, QMT and TFT scores and disease duration were examined using linear regression analysis. Results: The muscle weakness was symmetric and the neck flexors and the distal muscles of upper and lower extremities were weaker than proximal muscles. Using MMT scores, the average strength decline was $0.95 \%$ per year and was similar for men and women. The strength decline was significantly more rapid for distal muscles than for proximal muscles. Quantitative muscle testing scores documented a strength decline per year of disease duration of 1.2-1.6\% for the hip flexors and of 2.0-3.0\% for the hand grip flexors. Conclusions: We observed significant linear relationships between the scores generated by this protocol and disease duration. These data illustrate the distal to proximal progression of muscular involvement in DM, a pattern of progression well-recognized by the clinicians. The follow-up assessment of a large DM cohort in a longitudinal study will establish whether this quantitative protocol provides sensitive measures of the disease progression.
\end{abstract}

RÉSUMÉ: Évaluation motrice quantitative dans la dystrophie myotonique. Objectif: Établir des données de base au moyen d'un protocole d'évaluation motrice quantitative avant d'entreprendre une étude longitudinale prospective sur l'histoire naturelle de l'atteinte musculaire dans la dystrophie myotonique (DM). Plan et Méthodes: Nous avons effectué une étude transversale en utilisant un protocole comprenant une évaluation musculaire manuelle (ÉMM), une évaluation musculaire quantitative (ÉMQ) et une évaluation fonctionnelle chronométrée (ÉFC) chez 50 patients atteints de DM (27 hommes et 23 femmes), âgés de 16 à 67 ans. La relation entre les scores de l'ÉMM, l'ÉMQ et l'ÉFC et la durée de la maladie a été analysée au moyen de l'analyse de régression linéaire. Résultats: La faiblesse musculaire était symétrique et les fléchisseurs du cou et les muscles distaux des extrémités supérieures et inférieures étaient plus faibles que les muscles proximaux. Selon les scores de l'ÉMM, la diminution moyenne de la force était de $0,95 \%$ par année, tant chez les hommes que chez les femmes. La diminution de la force des muscles distaux était significativement plus rapide que celle des muscles proximaux. Les scores de l'ÉMQ ont montré une diminution de la force de 1,2 à 1,6\% au niveau des fléchisseurs de la hanche et de 2,0 à 3,0\% pour les fléchisseurs des doigts, par année de durée de la maladie. Conclusions: Nous avons observé une relation linéaire significative entre les scores générés par ce protocole et la durée de la maladie. Ces données illustrent la progression distale à proximale de l'atteinte musculaire dans la DM, ce qui est bien connu des cliniciens. L'étude longitudinale d'une grande cohorte de patients atteints de DM établira si on peut obtenir des mesures sensibles de la progression de la maladie au moyen de ce protocole quantitatif.

Can. J. Neurol. Sci. 2003; 30: 129-136

Myotonic dystrophy type 1 (DM), an autosomal dominant disorder, is the most common adult form of muscular dystrophy. Myotonic dystrophy results from an unstable cytosine, thymine, guanine (CTG)-repeat expansion in the 3' untranslated region of a myotonin kinase gene at $19 q 13.3 .{ }^{1}$ The clinical picture of DM includes ptosis and weakness of facial, jaw, and anterior neck muscles, distal weakness of the limbs progressing to proximal weakness, myotonia and involvement of other systems such as cataracts or cardiac conduction defects. ${ }^{2}$ The prevalence of DM ranges from 2.1 to 14.3 per 100,000 population world-wide, but a prevalence of 189 per 100,000 population has been reported in the Saguenay-Lac-Saint-Jean region (Quebec, Canada) where a common ancestor couple has been identified. ${ }^{3}$

The natural history and variable patterns of clinical progression of DM have not been well-delineated. There are no studies of objective means for quantifying disease progression.
The importance of natural history data in designing therapeutic trials is well-documented in studies of Duchenne muscular dystrophy, ${ }^{4}$ amyotrophic lateral sclerosis $(\mathrm{ALS})^{5-8}$ and facioscapulohumeral muscular dystrophy., 9

We conducted a cross-sectional study using a standardized protocol of manual muscle testing (MMT), quantitative muscle testing (QMT), and timed functional testing (TFT). The primary

From the Neuromuscular Clinic, Centre de réadaptation en déficience physique, Jonquière, QC, (JM, HB); Community Genomic Medicine Center, Montreal University, Montreal, QC, (JM); Laval University, Quebec, QC, (CLR) Canada ReCeived March 14, 2002. ACCePted in final fORm November 20, 2002. Reprint requests to: Jean Mathieu, Neuromuscular Clinic, Centre de réadaptation en déficience physique, Centre de Santé de Jonquière, 2230 rue de l'Hôpital, Jonquière, QC, G7X 7X2 Canada 
aim of this study is to establish baseline data prior to a prospective longitudinal study of the natural history of DM.

\section{Methods}

\section{Patients}

This study was conducted at the Neuromuscular Clinic of the Complexe Hospitalier de la Sagamie. The study protocol was approved by the institutional review board of the Complexe Hospitalier de la Sagamie. Data presented here were collected during the same sessions used for the assesssment of a diseasespecific muscular impairment rating scale in DM and published elsewhere. ${ }^{11}$ From a pool of 525 DM individuals followed at the Neuromuscular Clinic, we selected a sample of 50 patients to include approximately an equal number of subjects in each of the 10 -year age groups. Molecular confirmation of the diagnosis was obtained for all patients. Charts were reviewed to determine the age at onset of symptoms and the DM phenotype. ${ }^{12}$ Disease duration was defined as the delay between age at onset and time of the present study. In order to assure good cooperation from the participants, patients with a congenital form of DM were excluded from the study. Congenital DM patients were also excluded because the rate of progression of weakness is probably quite different in this group compared to the other DM phenotypes. $^{2}$

\section{Testing procedures}

\section{Manual muscle testing (MMT)}

We used the modified Medical Research Council Scale with a 0 to 10 point scoring system as described by Brooke et al. ${ }^{4}$ A total of 11 muscle groups were assessed, 10 of them bilaterally on each patient: six proximal muscle groups (shoulder abductors, elbow flexors, elbow extensors, hip flexors, knee extensors, knee

Table 1: Mean scores for manual muscle testing (MMT) and quantitative motor testing (QMT) of 50 DM patients with correlation ( $\mathrm{r}^{2}$ ) with disease duration, predicted values of the slopes of the linear regression and percentages of strength decline per year of disease duration.

\begin{tabular}{|c|c|c|c|c|c|c|c|c|c|}
\hline \multirow[b]{2}{*}{ Muscle group } & \multirow[b]{2}{*}{ Gender } & \multicolumn{2}{|c|}{ Score } & \multirow[b]{2}{*}{$\mathbf{r}^{2}$} & \multicolumn{4}{|c|}{ Slope of linear regression } & \multirow{2}{*}{$\begin{array}{c}\text { Decline per year } \\
\text { of disease duration }(\%)\end{array}$} \\
\hline & & Mean & \pm SD & & $\beta$ & $(95$ & bI ) & p & \\
\hline \multicolumn{10}{|c|}{ A) Manual muscle testing ( MMT) } \\
\hline \multirow{3}{*}{ Proximal muscles } & Men & 8.57 & 1.30 & 0.40 & -0.08 & $(-0.12$ & $-0.04)$ & 0.0004 & 0.80 \\
\hline & Women & 8.50 & 1.09 & 0.66 & -0.06 & $(-0.08$ & $-0.04)$ & $<0.0001$ & 0.61 \\
\hline & Total & 8.54 & 1.20 & 0.49 & -0.07 & $(-0.09$; & $-0.05)$ & $<0.0001$ & 0.71 \\
\hline \multirow[t]{3}{*}{ Distal muscles } & Men & 7.07 & 1.94 & 0.67 & -0.15 & $(-0.19$ & $-0.11)$ & $<0.0001$ & 1.54 \\
\hline & Women & 7.16 & 1.60 & 0.65 & -0.09 & $(-0.12$ & $-0.06)$ & $<0.0001$ & 0.99 \\
\hline & Total & 7.11 & 1.78 & 0.61 & -0.11 & $(-0.14$ & $-0.09)$ & $<0.0001$ & 1.19 \\
\hline \multirow[t]{3}{*}{ All muscles } & Men & 7.69 & 1.56 & 0.62 & -0.12 & $(-0.15$ & $-0.08)$ & $<0.0001$ & 1.23 \\
\hline & Women & 7.67 & 1.32 & 0.74 & -0.08 & $(-0.10$ & $-0.06)$ & $<0.0001$ & 0.86 \\
\hline & Total & 7.68 & 1.44 & 0.64 & -0.09 & $(-0.11$ & $-0.07)$ & $<0.0001$ & 0.95 \\
\hline \multicolumn{10}{|c|}{ B) Quantitative motor testing (QMT) } \\
\hline \multirow[t]{2}{*}{ Handgrip $(\mathrm{Kg})$} & Men & 16.33 & 13.48 & 0.74 & -1.09 & $(-1.35$ & $-0.82)$ & $<0.0001$ & 3.02 \\
\hline & Women & 12.39 & 7.59 & 0.62 & -0.42 & $(-0.57$ & $-0.27)$ & $<0.0001$ & 1.99 \\
\hline \multirow[t]{2}{*}{ Lateral pinch (Kg) } & Men & 4.96 & 2.85 & 0.68 & -0.22 & $(-0.28$ & $-0.16)$ & $<0.0001$ & 2.45 \\
\hline & Women & 3.58 & 1.46 & 0.54 & -0.08 & $(-0.11$ & $-0.04)$ & $\leq 0.0001$ & 1.55 \\
\hline \multirow[t]{2}{*}{ Elbow extensors $(\mathrm{Kg})$} & Men & 9.46 & 6.11 & 0.51 & -0.41 & $(-0.58$ & $-0.25)$ & $<0.0001$ & 2.42 \\
\hline & Women & 7.06 & 2.57 & 0.26 & -0.09 & $(-0.16$ & $-0.02)$ & $<0.05$ & 1.00 \\
\hline \multirow[t]{2}{*}{ Hip flexors $(\mathrm{Kg})$} & Men & 24.49 & 9.81 & 0.36 & -0.55 & $(-0.86$ & $-0.25)$ & $<0.001$ & 1.59 \\
\hline & Women & 17.60 & 5.80 & 0.46 & -0.28 & $(-0.41$ & $-0.14)$ & $<0.001$ & 1.20 \\
\hline \multirow[t]{2}{*}{ Ankle dorsiflexors (Kg) } & Men & 14.00 & 7.87 & 0.59 & -0.57 & $(-0.76$ & $-0.37)$ & $<0.0001$ & 2.35 \\
\hline & Women & 12.03 & 5.71 & 0.34 & -0.24 & $(-0.38$ & $-0.08)$ & $<0.0001$ & 1.42 \\
\hline
\end{tabular}

Unit decline per year of disease duration was determined from slope $(\beta)$ of the linear regression line. 
flexors) and four distal muscle groups (wrist extensors, digit flexors, ankle dorsiflexors and ankle plantar flexors). The neck flexors were tested both at the same time and a separate but similar score was produced for right and left. In addition to a total muscle score (maximum of 220 points), average scores were obtained for proximal muscles (maximum of 120 points), distal muscles (maximum of 80 points), upper limb muscles (maximum of 100 points) and lower limb muscles (maximum of 100 points). The results of these five different muscle scores are presented on a 0 to 10 -point scale (the observed score divided by the maximum possible total score, mutiplied by 10) and are the average of four evaluations. ${ }^{11}$ The intrarater and interrater reliabilities of the total MMT score were found to be quite high $(\mathrm{ICC}=0.93$ and 0.87$){ }^{11}$

\section{Quantitative muscle testing (QMT)}

Bilateral grip strength was measured using a Jamar dynamometer (Asimow Engineering Co., Los Angeles, CA). The patient was seated with the elbow at 90 degrees and with the forearm not resting on the thigh. Lateral pinch between the thumb and index finger was tested using a pinch gauge (Baseline Pinch Gauge, Fabrication Enterprises Inc, Irvington, NY). The patient pinched the gauge between the tip of the thumb and the lateral surface of the index finger. An electronic hand-held dynamometer (Nicholas MMT, Lafayette, IN) was used to measure the maximal isometric force of three muscle groups bilaterally: extension at the elbow, flexion at the hip and dorsiflexion at the ankle. The mean of the peak force generated during two trials was recorded for each of the tests.

\section{Timed functional testing (TFT)}

We used the Appel's ALS rating scale ${ }^{13}$ to assess timed tasks involving the upper and the lower extremities. Lower extremity tasks were: 1) to stand erect from a sitting position in a standard chair, 2) to rise from a supine position, 3) to walk 20 feet, with assistive devices if necessary and 4) to climb and descend four standard steps, again with assistive devices if necessary. Assistance by others is not allowed in any of these timed tasks. For the upper extremity functions, the time required to perform the following tasks was recorded: 1) to propel a wheelchair 20 feet, 2) to cut a piece of $1 / 4$-inch-thick Theraplast with a plastic knife which is positioned in the dominant hand at the beginning of the test, 3 ) to assemble peg units (consisting of a pin, followed by a washer, followed by a collar) on a Purdue pegboard during a period of 60 seconds (seconds per peg) and 4) using one hand at a time, to turn blocks, $2 \frac{1}{2}$ inches in diameter and $3 / 4$ inch high, on a board during a period of 60 seconds (seconds per block). The results presented in this study are the average of two evaluations. ${ }^{11}$ Test-retest reliability for the eight timed functional tests were found to be substantial to almost perfect. ${ }^{11}$

\section{Statistical analysis}

The relationships between MMT, QMT and disease duration and between TFT and MMT scores were examined using linear regression analysis. Correlations between MMT/QMT scores and disease duration as well as TFT scores and MMT subscores for upper or lower limbs muscles were assessed using Spearman rank correlation coefficients with one-tailed significance. A p value less than 0.05 was considered significant.

To determine the sample size estimates for a future longitudinal study, we used the standard deviation of scores generated by this cross-sectional study. ${ }^{14}$ We used paired t-tests one-tail because the alternative hypothesis is that MMT or QMT scores generated after five years of observation will be less than those of the baseline. The magnitude of the difference to be detected in five years was determined by the slope of the linear regressions. We assumed the probability of a Type I error of 0.05 and a Type II error of 0.10 .

Statistical analyses were performed using the SPSS statistical software package. ${ }^{15}$

\section{RESUlts}

\section{Baseline characteristics of the study population}

Patients included 27 men and 23 women. Mean age at the time of the study was 41.1 years $(\mathrm{SD} \pm 12.8$ years, range 16-67 years), mean age at onset of symptoms was 17.9 years $(\mathrm{SD} \pm 8.8$ years, range 5-47 years) and median disease duration was 19.3 years ( $\mathrm{SD} \pm 12.3$ years, range $0-55$ years). The frequency distribution of the CTG-repeat sizes is the following: $<200$ repeats $(16 \%), 201-400$ repeats $(2 \%), 401-850$ repeats $(30 \%)$, $851-1100$ repeats $(16 \%), 1101-1500$ repeats $(18 \%)$ and $>1500$ repeats $(18 \%)$. The DM phenotype, according to the age at onset of symptoms, ${ }^{12}$ was distributed as follows: $12 \%$ of infantile form, $48 \%$ of early adult form, $24 \%$ of the adult form and $16 \%$ of mild or late form. Forty-eight (48) of the 50 patients were ambulant at the time of the study and none presented a severe proximal weakness.

\section{Manual muscle testing}

Figure 1 shows the distribution of the MMT grades for each of the 11 muscles tested. The weakness is symmetric for all muscle groups. The neck flexors and the distal muscles of upper and lower extremities are prominently involved. The average MMT scores were 8.54 (SD \pm 1.20 ) for proximal muscle group, $7.11(\mathrm{SD} \pm 1.78)$ for distal muscle group and $7.68(\mathrm{SD} \pm 1.44)$ for the total MMT score (Table 1).

The muscle strength as expressed by the MMT total score is highly correlated with the disease duration (Pearson $r=-0.79$, $\mathrm{p}<0.0001)$. As the disease duration is also highly correlated with the CTG-repeat sizes (Spearman $r=-.56, p<0.0001$ ), it is not surprising to find a significant correlation between the MMT total score and the CTG-repeat sizes (Spearman $\mathrm{r}=-0.56, \mathrm{p}<0.0001$ ).

To determine the rate of disease progression in relation to disease duration, linear regression analyses were performed using the MMT total score and proximal and distal MMT subscores. The regression model documented a significant linear decrease in muscle strength over time for the total muscle score (Figure 2A) and for proximal and distal muscle scores (Figure 2B). The neck flexor muscle score is not illustrated in this figure because the linear regression model is not the model of choice to express the neck flexor strength decline over time; we observed a rapid decline of the strength during the first 20 years of disease duration and then a stabilisation. The rate of decline of the MMT total score of this group of DM patients is -0.09 units/year $(0.95 \% / y e a r)$ (Table 1$)$. The decline was significantly $(\mathrm{p}<0.05)$ more important for distal muscles (-0.11 units/year or $1.19 \%$ / year) than for proximal muscles (-0.07 units/year or $0.71 \% /$ year) and was not significantly different for men and women. 


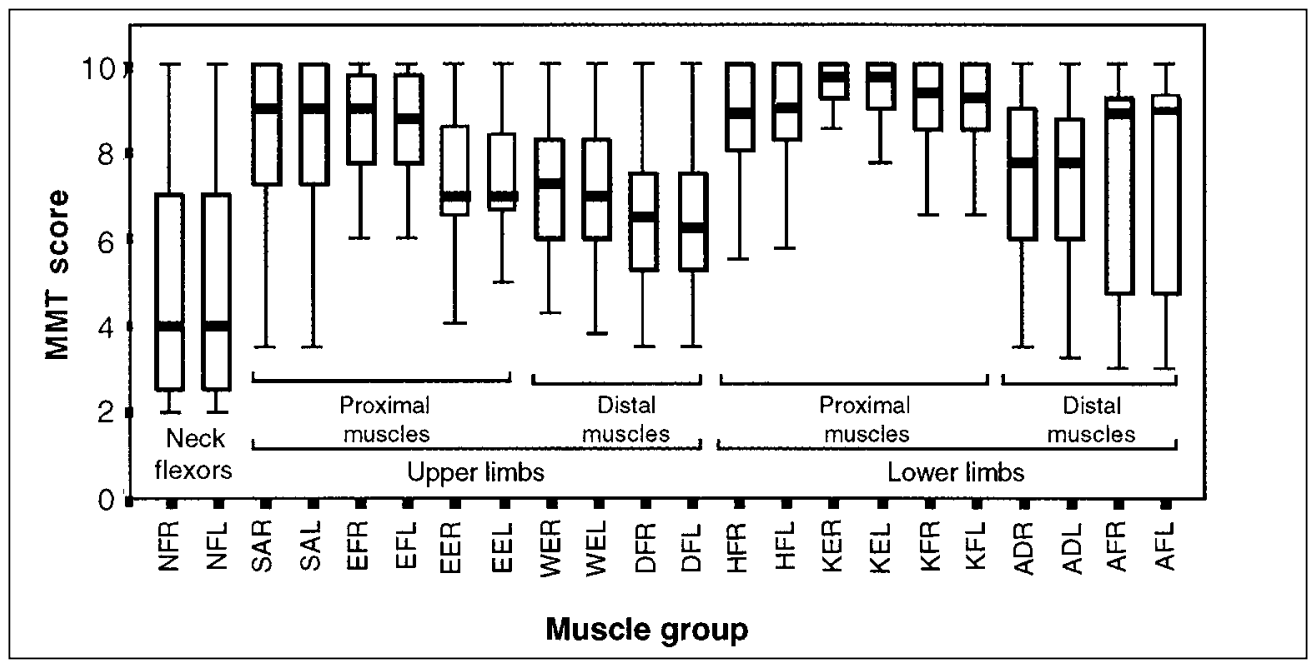

Figure 1: Boxplots illustrating manual muscle testing (MMT) scores for individual muscle groups in 50 DM patients. Box extends from 25th to 75th percentile. The line is the median. Whiskers extend to largest and smallest observed values within 1.5 box lengths. $N F=$ neck flexor; $S A=$ shoulder abductor; $E F=$ elbow flexor; $E E=$ elbow extensor $; W E=$ wrist extensor; $D F=$ digits flexor; $H F=$ hip flexor; $K E=$ knee extensor; $K F=$ knee flexor; $A D=$ ankle dorsiflexor; $A F=$ ankle plantar flexor. The third letter of each abbreviation refers to side ( $R=$ right, $L=$ left $)$.

\section{Quantitative motor testing}

Table 1 shows the isometric strength measures for male and female patients. A gender effect was noted for all muscles; the strength of female subjects was less than in male subjects. The linear regression model according to disease duration documented a significant linear strength decline for all measurements. The decline of strength per year of disease duration varied from 1.2-1.6\% for a proximal muscle group like the hip flexors to $2.0-3.0 \%$ for a distal muscle group like the hand grip flexors.

\section{Timed functional testing}

Mean scores of timed functional tasks for the $50 \mathrm{DM}$ patients are shown in Table 2. We documented a nonlinear relationship between functional tests and corresponding upper or lower limbs MMT subscores and QMT scores. After logarithmic transformations of the TFT, the relations were found to be linear (Figure 3 and 4) and the correlations were statistically significant. The variance in strength of upper or lower limbs explains as much as $31-68 \%$ of the variance in the time taken to perform the tasks. Among all functional tasks, the highest correlation with the MMT scores was found for climbing and descending four steps $\left(r^{2}=0.68\right)$ and cutting theraplast $\left(r^{2}=0.61\right)$. Adding age, sex or disease duration to the multiple regression did not result in higher correlation coefficient values for any of these eight functional tasks. The same linear relationship was also found between QMT scores and functional tasks (Figure 4) with correlations similar to those observed with MMT. This suggests that both QMT and MMT are relatively good predictors of functional disability with no advantage of one over the other.

\section{Discussion}

The quantitative protocol used in the present study is partly derived from those designed for ALS, Duchenne muscular

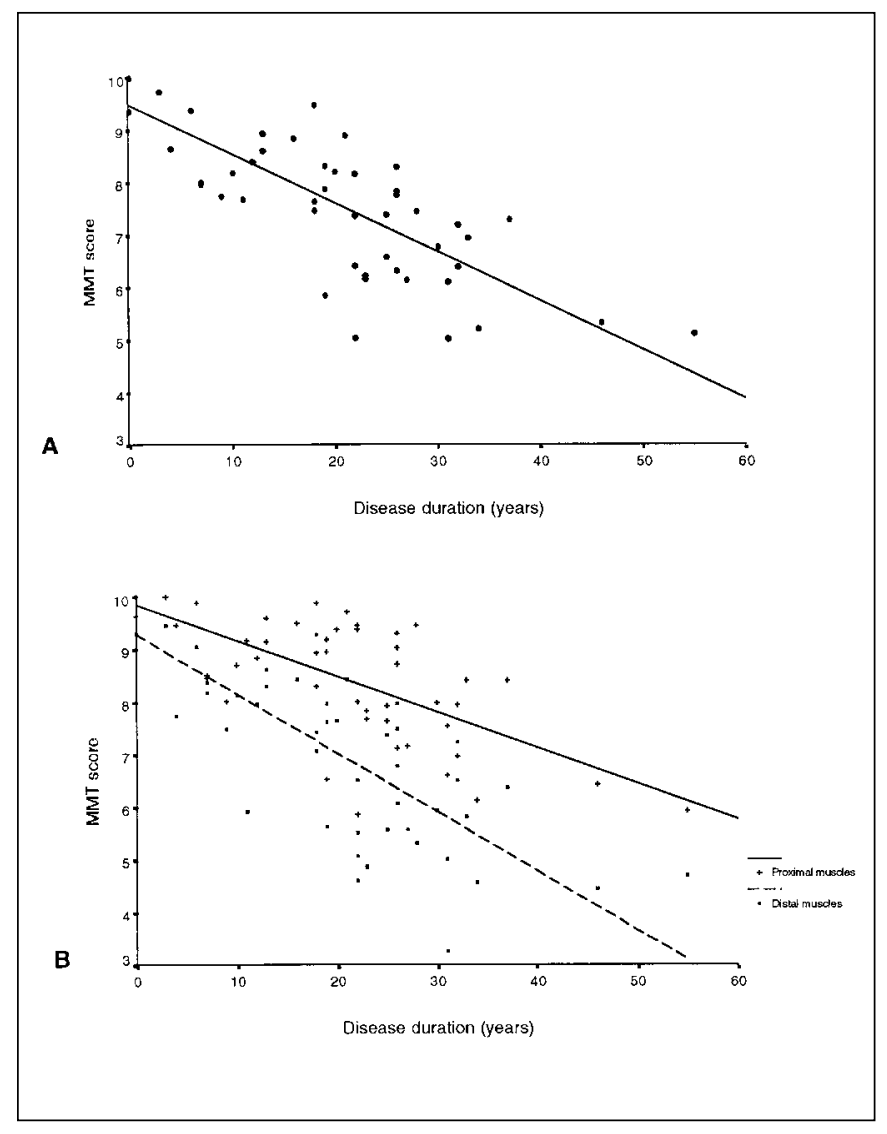

Figure 2: A scatter plot and linear regression lines of average MMT scores for the total muscle score (A) and for proximal and distal muscle scores $(B)$ versus disease duration for 50 DM patients. The slopes of the regression lines differ significantly for proximal muscles and distal muscles. 

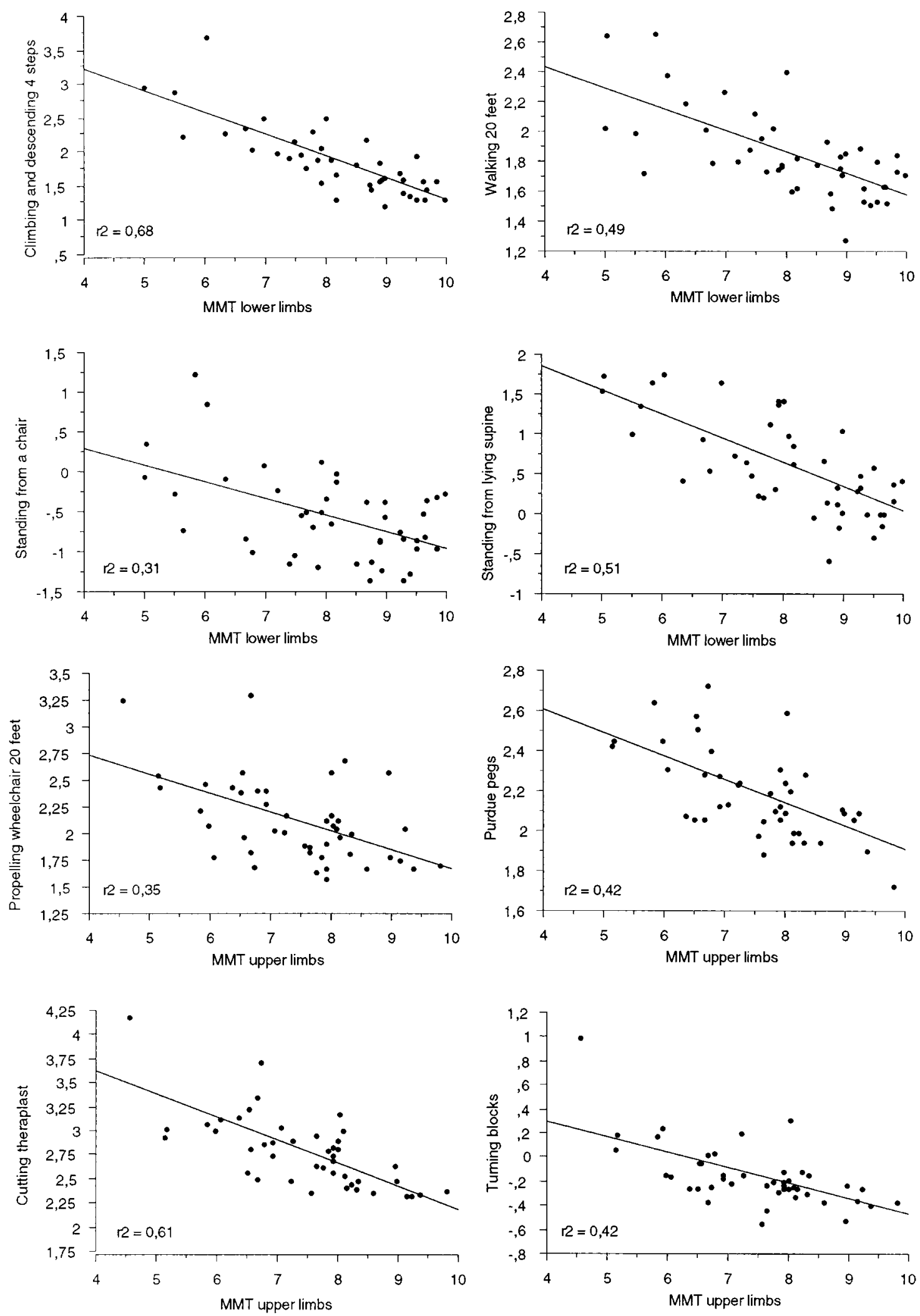

Figure 3: Relation between timed functional tasks (TFT) and manual muscle testing (MMT) scores for lower or upper limbs. TFT data are presented after logarithmic transformation. Each data point represents one subject. 
Y

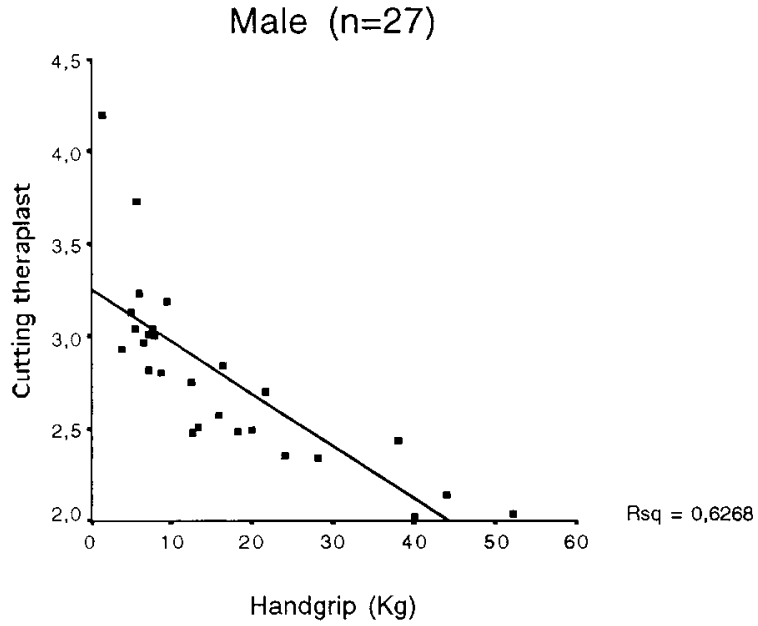

Male $(n=27)$

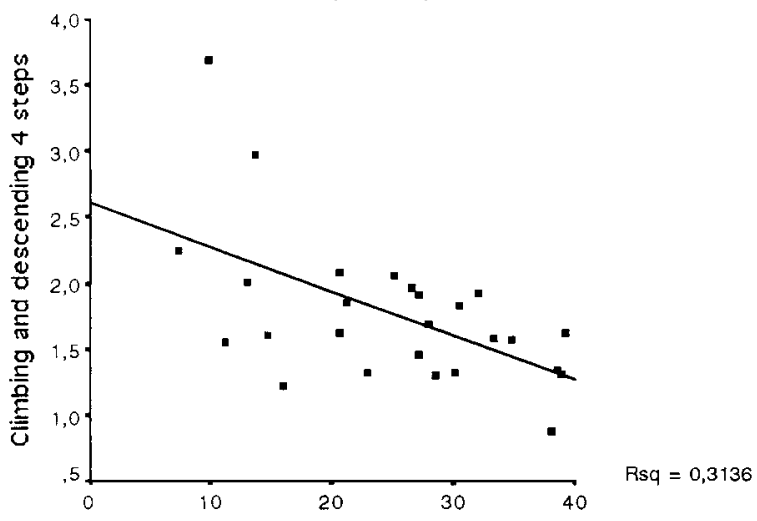

Hip flexors $(\mathrm{kg})$
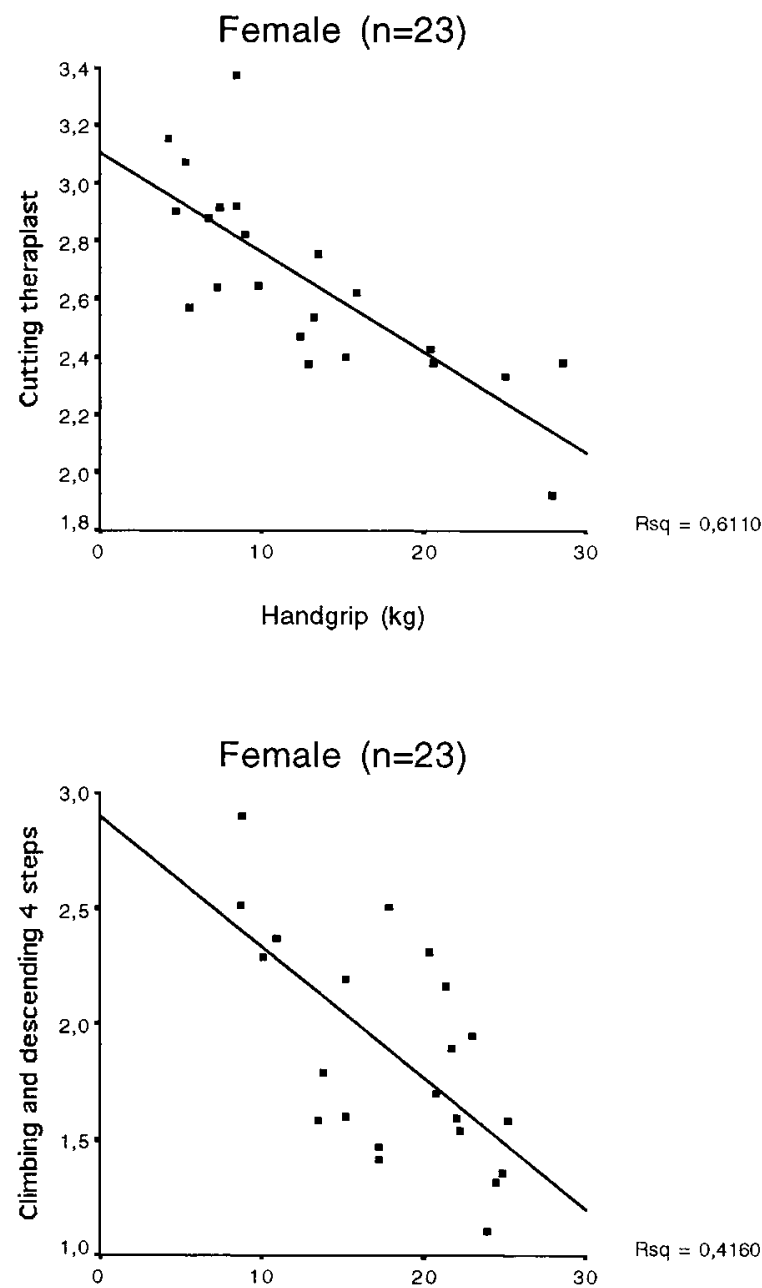

Hip flexors $(\mathrm{kg})$

Figure 4: Relations according to gender between some timed functional tasks (TFT) and appropriate quantitative muscle testing (QMT) scores. TFT data are presented after logarithmic transformation. Each data point represents one subject.

Table 2: Scores of timed functional tests (TFT) of 50 DM patients.

\begin{tabular}{|c|c|c|c|c|c|c|}
\hline \multirow[b]{2}{*}{ Functional test } & \multicolumn{2}{|c|}{ Men } & \multicolumn{2}{|c|}{ Women } & \multicolumn{2}{|c|}{ Total } \\
\hline & Mean (SD) & Range & Mean (SD) & Range & Mean (SD) & Range \\
\hline Propelling wheelchair 20 feet $(\mathrm{sec})$ & $7.9(4.3)$ & $3.7-26.3$ & $9.9(4.8)$ & $5.1-27.8$ & $8.8(4.6)$ & $3.7-27.8$ \\
\hline Cutting Theraplast - dominant hand (sec) & $18.6(11.9)$ & $7.6-66.5$ & $15.1(5.1)$ & $6.8-29.1$ & $17.0(9.6)$ & $6.8-66.5$ \\
\hline Purdue peg board (sec per peg) & $9.5(2.3)$ & $5.8-15.3$ & $8.3(1.9)$ & $5.7-14.1$ & $9.0(2.2)$ & $5.7-15.3$ \\
\hline Turning blocks (sec per block) & $0.9(0.4)$ & $0.6-2.7$ & $0.8(0.2)$ & $0.5-1.3$ & $0.9(0.3)$ & $0.5-2.7$ \\
\hline Standing from chair $(\mathrm{sec})$ & $0.8(0.7)$ & $0.3-3.5$ & $0.6(0.3)$ & $0.3-1.5$ & $0.7(0.5)$ & $0.3-3.5$ \\
\hline Standing from lying supine (sec) & $2.2(1.5)$ & $0.8-5.9$ & $2.0(1.4)$ & $0.5-5.7$ & $2.1(1.4)$ & $0.5-5.9$ \\
\hline Walking 20 feet (sec) & $6.1(2.1)$ & $3.6-14.4$ & $6.9(2.4)$ & $4.4-14.3$ & $6.5(2.3)$ & 3.6-14.4 \\
\hline Climbing and descending 4 steps (sec) & $7.4(7.5)$ & 2.4-40.4 & $7.3(3.8)$ & $3.0-18.2$ & $7.3(6.0)$ & 2.4-40.4 \\
\hline
\end{tabular}


Table 3: Sample size estimates based on MMT total score, MMT scores according to CTG expansion sizes and QMT.

$\begin{array}{llll}\text { Gender } & \text { SD } & \beta & \text { n }\end{array}$

A) MMT

Total score

$1.44-0.08$

$\leq 400$ CTG repeats

401-1100 CTG repeats

0.73

$-0.08$

1.22

$-0.07$

$-0.08$

1.16

$-0.07$

88

37

$>1100$ CTG repeats

B) QMT

Handgrip

Men

13.48

$-1.09$

52

Women

7.59

$-0.42$

112

Hip flexors

Men

9.81

$-0.55$

108

Women

5.80

$-0.28$

146

SD: standard deviation of the mean score

$\beta$ : slope of linear regression

$\mathrm{n}$ : sample size estimate

dystrophy and facioscapulohumeral muscular dystrophy. ${ }^{4-10}$ The usual distal to proximal progression of muscular involvement in DM and the very slow strength decline distinctive of this disease prompted us to elaborate a more specific quantitative protocol. The ideal method to document the natural history of a progressive neuromuscular disease should be inexpensive, easy to use in a clinical setting, reproducible, and reflect accurately the course of the illness. ${ }^{16}$ As in other neuromuscular disorders, standardization of testing procedures and determination of the reliability of measurements must precede a prospective longitudinal study of the natural history of DM.

\section{Manual muscle testing}

The manual muscle test is an accepted method of evaluating muscle strength. ${ }^{17}$ The MMT is quickly performed and inexpensive. Scores on the MMT can be dependent upon the evaluator: differences in evaluator strength and weight of the subjects' limbs are potential factors affecting MMT grades. ${ }^{18} \mathrm{An}$ additional limitation of the MMT scoring system used in the present study is its 10-point grading system with the same value given for grade $-4,4$ and +4 , thus reducing the responsiveness of the strength changes in this category. Also, some argue that the quantitative capacity of the MMT is severely limited because it provides only ordinal data. To counteract this limitation, the Clinical Investigation of Duchenne Dystrophy group obtained interval data by using an average muscle score, thus rending this method suitable for therapeutics trials. ${ }^{4,17}$

The results of this cross-sectional study confirm the very slow progression of the muscular involvement in DM with a muscle strength decline of 0.09 units per year of disease duration or roughly $1 \%$ per year. In the cross-sectional part of a study of 75 noncongenital patients and using a 0 to 5 points MMT scale, Johnson ${ }^{19}$ found a decline of 0.36 units per decade of age and, surprisingly, no significant decrease in strength with respect to the disease duration, likely due to misreporting of the age at onset of symptoms. Strength usually decreases with age in healthy subjects but, unlike the disease duration, age contributes marginally in the regression analysis to explain the decline of strength in DM over time.

\section{Quantitative motor testing}

The Clinical Investigation of Duchenne Dystrophy group also documented that individual muscle MMT scores do not show a linear rate of decline and stated that MMT should not be used in therapeutic trials based on the assessment of individual muscle strength. ${ }^{17}$ Quantitative testing is being used increasingly to measure muscle strength in neuromuscular disorders. ${ }^{18}$ Whether or not QMT is superior to MMT in term of usefulness for individual assessment or in therapeutic trials is still open to question. ${ }^{17,20}$ Isometric strength measurements, using straingauge tensiometers, usually produce reliable and valid interval data. ${ }^{21}$ The primary disadvantage of a hand-held myometer is its dependence on the strength of the examiner. Otherwise, the ability of the present QMT protocol to test very weak muscle groups (range from -3 to 2 ) cannot be addressed because the cohort of DM patients evaluated in the study were all ambulant and none presented severe weakness.

The decline of strength per year of disease duration observed from QMT supported the conclusions of the MMT: a slow significant linear strength decline over time and a faster decline for distal muscles than for proximal muscles.

\section{Timed functional tasks}

Several timed functional tests have been used to characterize the natural history of neuromuscular disorders and to measure the efficacy of therapeutic agents in clinical trials. ${ }^{16}$ The standardized TFT used in the present study were easy to perform, inexpensive and reliable. Timed functional tests are also useful to follow the course of DM with high degree of interrater reliability. ${ }^{22} \mathrm{~A}$ major limitation of TFT is that timing a single task may not be appropriate for all stages of the disease and lacks the sensibility to detect subtle changes in strength. ${ }^{21}$ Another problem with timed tests is that they are affected by the patient's mood and ability to cooperate, as well as functional state. ${ }^{4}$

A significant relationship between strength as measured by MMT or QMT and TFT was demonstrated in this study. Lindeman ${ }^{23}$ also documented a strong relationship between muscle strength (quadriceps) and timed motor performances in DM patients. However, a perfect correlation was not to be expected in DM because motor performances may be influenced by other factors, such as reduced mobility due to contractures, disturbance in muscle tone, use of walking aids and orthoses and reduced mental level. ${ }^{23}$ Also, some timed motor tasks, such as rising from supine, demand activation of many muscles not restricted to upper or lower limbs: trunk, arm, leg and even neck musculature is used to perform this function. ${ }^{23}$

\section{CONSIDERATIONS FOR FUTURE RESEARCH}

This cross-sectional study detected a significant average decline among the patients as measured by MMT and QMT 
scores, consistent with the notion that DM is a very slow progressive disorder.

The data obtained on this cross-sectional study were useful to determine the required sample size for a longitudinal study. Table 3 presents the sample size estimates based on observed MMT and QMT scores. We estimate that a sample size of \pm 100 patients would be required to provide $90 \%$ power to detect a difference in mean change of 0.4 units of the total MMT score over a five year period, assuming a type I error of $5 \%$. This estimate of the sample size remains identical regardless of the severity of muscle involvement according to CTG expansions. Functional deterioration in DM have been documented over a two year period using simple tests such as measurements of hand-grip strength and walking speed. ${ }^{24}$ However, we propose a five year period of observation because two to three years may be too narrow a window to define the natural history of a slowly progressive disease like DM, in contrast to more progressive diseases such as ALS or Duchenne dystrophy and such a short period of observation would require a much larger sample size. As the study excluded patients with congenital DM, these estimates of sample size are not valid for this category of patients.

Future work will concentrate on the construction of composite scores using normative data and adding a larger set of distal muscles. A MMT score based on a larger number of distal muscles should be more sensitive to change. A longitudinal study will be essential to establish whether this quantitative protocol provides sensitive measures of the disease progression, to confirm the linearity of disease progression, to determine the rate of decline through all stages of the disease, to identify useful predictors of disease progression and to provide implications for the design and implementation of therapeutic trials in DM. This knowlege will also be essential to confirm if this quantitative protocol is well-suited for natural history controlled trials. ${ }^{8}$

\section{ACKNOWLEDGEMENTS}

Supported by the Fonds de la Recherche en Santé du Québec

\section{REFERENCES}

1. Harley HG, Brook JD, Rundle SA, et al. Expansion of an unstable DNA region and phenotypic variation in myotonic dystrophy. Nature 1992;355:545-546.

2. Harper PS. Myotonic dystrophy. 3rd ed. London: W.B.Saunders, 2001.

3. Mathieu J, DeBraekeleer M, Prévost C. Genealogical reconstruction of myotonic dystrophy in the Saguenay-Lac-Saint-Jean area (Quebec, Canada). Neurology 1990;40:839-842.

4. Brooke MH, Fenichel GM, Griggs RC, et al. Clinical investigation in Duchenne dystrophy: 2. Determination of the "power" of therapeutic trials based on the natural history. Muscle Nerve 1983;6:91-103.

5. Munsat TL, Andres PL, Finison L, Conlon T, Thibodeau L. The natural history of motoneuron loss in amyotrophic lateral sclerosis. Neurology 1988;38:409-413.

6. Andres PL, Finison L, Conlon T, Thibodeau L, Munsat TL. Use of composite scores (megascores) to measure deficit in amyotrophic lateral sclerosis. Neurology 1988;38:405-408.

7. Pradas J, Finison L, Andres PL, et al. The natural history of amyotrophic lateral sclerosis and the use of natural history controls in therapeutic trials. Neurology 1993;43:751-755.

8. Munsat TL. Issues in clinical trial design 1: use of natural history controls. A protagonist view. Neurology 1996;47:S96-S97.

9. Tawil R, McDermott MP, Mendell JR, et al. Facioscapulohumeral muscular dystrophy (FSHD): design of natural history study and results of baseline testing. Neurology 1994;44:442-446.

10. The FSH-DY Group. A prospective quantitative study of the natural history of facioscapulohumeral muscular dystrophy (FSHD): implications for therapeutic trials. Neurology 1997;48:38-46.

11. Mathieu J, Boivin H, Meunier D, Gaudreault M, Bégin P. Assessment of a disease-specific impairment rating scale in myotonic dystrophy. Neurology 2001; 56(3):336-340.

12. Koch MC, Grimm T, Harley HG, Harper PS. Genetic risk for children of women with myotonic dystrophy. Am J Hum Genet 1991;48:1084-1091.

13. Appel V, Stewart SS, Smith G, Appel SH. A rating scale for amyotrophic lateral sclerosis: description and preliminary experience. Ann Neurol 1987;22:328-333.

14. Fisher LD, Van Belle G. Biostatistics. A methodology for the Health Sciences. John Wiley and Sons, New York, 1993.

15. SPSS Advanced and Professional Statistics 6.1., Chicago, IL. SPSS Inc., 1994.

16. Moxley RT. Functional testing. Muscle Nerve 1990 (Suppl): S26-S29.

17. Mendell JR, Florence J. Manual muscle testing. Muscle Nerve 1990 (Suppl): S16-S20.

18. Personius KE, Pandya S, King WM, Tawil R, McDermott MP and the FSH DY Group. Facioscapulohumeral dystrophy natural history study: standardization of testing procedures and reliability of measurements. Phys Ther 1994;74 :253-263.

19. Johnson ER, Abresch RT, Carter GT, et al. Profile of neuromuscular diseases: myotonic dystrophy. Am J Phys Rehabil 1995;74(Suppl 5):S104-S116.

20. FSH-DY Group. A prospective, quantitative study of the natural history of facioscapulohumeral muscular dystrophy (FSHD): implications for therapeutic trials. Neurology 1997;48:38-46.

21. Andres PL, Hedlund W, Finison L, et al. Quantitative motor assessment in amyotrophic lateral sclerosis. Neurology 1986;36:937-941.

22. Griggs RC, Pandya S, Florence JM et al. Randomized controlled trial of testosterone in myotonic dystrophy. Neurology 1989;39: 219-222.

23. Lindeman E, Leffers P, Reulen J, Spaans F, Drukker J. Quadriceps strength and timed motor performances in myotonic dystrophy, Charcot-Marie-Tooth disease, and healthy subjects. Clin Rehabil 1998;12:127-135.

24. Orndahl G, Grimby G, Grimby A, Johansson G, Wilhelmsen L. Functional deterioration and selenium-vitamin $\mathrm{E}$ treatment in myotonic dystrophy. A placebo-controlled study. J Intern Med 1994;235:205-210. 